\title{
Series preface
}

This is the first volume in the new NORRAG Series on International Education and Development. The books in the series intend to generate an international debate on emerging trends in education and provide space for authors who represent diverse perspectives and knowledge communities. The first volume opens new horizons on the debate about public-private partnerships in education as they diversify, expand and increasingly blur the distinction between the public and private sectors.

The series reflects the mission of the global Network for International Policies and Cooperation in Education and Training (NORRAG) to produce, disseminate and broker critical knowledge on topical issues that emerge in education and development. Through its programs, knowledge production and dissemination, NORRAG contributes to enhancing the conditions for participatory, informed, and evidence-based policy decisions that improve equity and quality of education. In fact, the series aims to serve as a knowledge broker at the interface between research, policy and practice within the comparative, development and international education community.

NORRAG undertakes its activities with partners, and its books will generally bear the stamp of several institutions. This particular book greatly benefited from a partnership with Education International (EI) and with the Open Society Foundations (OSF). Both organizations have for years supported research initiatives that investigate the impact of privatization on public education. In 2016 and 2017, the three organizations, EI, OSF and NORRAG, joined forces to support and disseminate research on the topic.

Several decades after the introduction and promotion by powerful international organizations and bilateral donors of PPPs in education, the reciprocal influence of the public and private sectors has seen the two come to behave similarly in many regards. This book 
brings together new country-level research from Argentina, Bangladesh, Brazil, China, Rwanda, countries recipient of refugees from Syria, and the USA. The country research is framed by two chapters that present, first, a broad-scale analysis of a growing trend that weakens international and national commitments to the right to free and relevant education and blurs the boundaries between public and private goods, and second a framework for assessing the legitimacy and effectiveness of public-private partnerships.

Gita Steiner-Khamsi Series Editor, New York and Geneva 
Gita Steiner-Khamsi and Alexandra Draxler - 9781788970334 Downloaded from PubFactory at $04 / 26 / 2023$ 02:56:40PM 